\title{
A new bi-objective mixed integer linear programming for designing a supply chain considering CO2 emission
}

\author{
Mohammad Mahdi Saffar*, Hamed Shakouri G. and Jafar Razmi
}

Collage of Industrial and Systems Engineering, University of Tehran, Tehran, Iran

\begin{tabular}{|c|c|}
\hline C H R O I C L E & A B S T R A T \\
\hline $\begin{array}{l}\text { Article history: } \\
\text { Received December 10, } 2013 \\
\text { Received in revised format } \\
16 \text { June } 2014 \\
\text { Accepted June } 252014 \\
\text { Available online } \\
\text { June } 302014 \\
\text { Keywords: } \\
\text { Closed loop supply chain network } \\
\text { design } \\
\text { Environmental optimization } \\
\text { Multi objective fuzzy programming } \\
\text { Operational risks } \\
\text { NSGA }\end{array}$ & $\begin{array}{l}\text { Nowadays, the advance and enhance in competitive area, convert the supply chain management } \\
\text { into one of the most important issues for industries, organization, and firms. Increasing the } \\
\text { quality of products, decreasing the costs, and representing the satisfying service are the primary } \\
\text { objectives of organization and managers. Apart from that, the amount of CNGs (such as } \mathrm{CO}_{2} \text { ) } \\
\text { has been raised by industrial activities. Therefore, the concern of air pollution motivates } \\
\text { managers and researchers to consider this issue in the process. This paper represents a multi } \\
\text { objective supply chain network fuzzy programming, which is multi product, multi period, } \\
\text { multi-layer, and has reverse product network. Operational risks are considered as deficiency in } \\
\text { suppliers' units and production center. The model's duty is to choose the optimal suppliers } \\
\text { based on different factors such as selling price, the average of deficiency and transportation } \\
\text { costs. In order to solve the model, the Jimenez and TH approach are used and for large-scale } \\
\text { problems, the paper uses the NSGA-II algorithm. }\end{array}$ \\
\hline
\end{tabular}

\section{Introduction}

Supply chain management is managing all procedures from the start to the customers and includes the whole of network from extracting materials to the end of the salvage value of products. Some go further and bring recycling wastage into the supply networks. Recently, because of the advancement in connection, the competitive area in which organizations compete has been expanded, expeditiously. Consequently, the significance of designing and using an optimal and economic supply chain networks have increased, substantially. Planning a network based on strategic factors and customer demands in necessary (Daskin, 1995). One of the significant greenhouse gases emitted through human activity is carbon dioxide $\left(\mathrm{CO}_{2}\right)$. Increasing $\mathrm{CO}_{2}$ emission becomes an important issue for the natural cycle in ecosystem as the nature keeps the equilibrium between the quantity of $\mathrm{CO}_{2}$ refined and the quantity of $\mathrm{CO}_{2}$ unleashed; thus, human activity is accountable for that rising has come about. In other hand, supply chains contain various activities such as production, shipment, recovery etc. Therefore, it seems important to consider environmental issue like $\mathrm{CO}_{2}$ emission in designing a supply chain network.

* Corresponding author

E-mail address: $\underline{\text { m.saffar@ut.ac.ir }}$ (M. M. Saffar)

(C) 2014 Growing Science Ltd. All rights reserved. doi: $10.5267 /$ j.uscm.2014.6.001 
One of the most important decisions in supply chain design is associated with decisions in strategic level. In this level, designing the network, locating facilities, and assigning the flows of goods among the chosen facilities are of a great significance. In discrete location problems, there are a limited number of locations, which can be chosen as locations for establishing new facilities. The simplest problems in network design are locating $P$ new facilities in a way that the summation of distances or cost of resources is minimized. These problems in literature reviews are known as facility location problems without considering capacity constraints. In these models, each customers are assigned to a facilities in a form that the total cost can be minimized (Melo et al., 2009).

Melkate and Daskin (2001) made the first efforts in supply chain network design. They represent a single-period facility location model with considering capacity constraints. Drenzner and Wesolowsky (2003) introduced single-layer single-period location to optimize transportation costs, and facilities allocation costs. Ambrosino and Acutella (2005) solved a dynamic four-layer multiperiod under uncertainty. Thanh et al. (2008) modeled a dynamic model with integrate such parameters as demands, selling price, facility foundation costs, and transportation in different periods as a mathematical problem. The common supply chain models take no responsibility for products after they are given to customers. However, the advancement in competitive area makes organization to use reverse logistic, not only to attract new customers, but also not to lose their customers. Among the recent research, Fleischmann et al. (1997) introduced a comprehensive survey on the application of mathematical modeling in reverse supply chain management and Klibi et al. (2010) conducted a survey on supply chain network design problems to demonstrate future research directions. Barros et al. (1998) presented a MILP model for a sand recycling network solved by a heuristic algorithm. Jayaraman et al. (1999) presented a MILP model for reverse supply chain network design based on customer demands for recovered products. The goal of the presented model was to minimize the traditional costs.

Jayaraman et al. (2003) developed their previous work to model the single product two-level hierarchical location problem considering the reverse logistics operations of hazardous products. They also extend a heuristic to solve large-sized problem. The design of forward and reverse logistics networks has a strong impact on the performance of each other. Thus, to avoid the suboptimality caused by the separated design, the design of the forward and reverse supply chain networks should be integrated (Pishvaee et al., 2010). Pati et al. (2008) introduced a mixed-integer goal programming model for paper recycling supply chain network design. The aims of objective functions are: (1) minimizing the positive deviation from the specified budget (2) minimizing the negative deviation from the minimum planned waste collection and (3) minimizing the positive deviation from the maximum limit of wastepaper.

$\mathrm{Lu}$ and Bostel (2007) represented a three-layer design network with the goal of locating facilities in reverse logistic, in addition to minimize the traditional costs. Apart from that, in a paper published by Pishvaee et al. (2009) a reverse logistic model minimized transportation costs, facility location costs. Pishvaee et al. (2011), in other work, introduced a model by considering forward and reverse flows, simultaneously. In this paper, a bi-objective model is solved; the first objective function reducing fixed cost, and the second objective function increases satisfaction level. The forward flow is related to product distribution. In addition, backward flow is associated with collecting returned products. Sayed et al. (2010) provided an integrated logistic _forward and backward_to locate distribution and collection centers. Pishvaee and Razmi (2012) developed a multi-objective fuzzy reverse supply chain minimizing economic costs as well as optimizing $\mathrm{CO}_{2}$ emission. In same year, Pishvaee et al. (2012) introduced a bi-objective model with the capability of optimizing socio-economic effects. Ilgin and Gupta (2010) presented a comprehensive review on company's conscious about environment and product recycle and recovery. Because of the lack of historical data in real cases that is rarely available and the high computational complexity, the use of stochastic programming models seems to be impossible in real cases. Therefore, in recent years a few number of papers used more flexible approaches such as fuzzy programming (e.g. Wang \& Hsu, 2010). Pishvaee and Razmi 
(2012) also proposed a mathematical model for single product and single period supply chain network. Environmental issue is considered in their model. Hassanzadeh Amin and Zhang (2013) and Özkır and Başligil (2013) studied on a forward-backward supply chain but the presented model ignore environmental issues such $\mathrm{CO}_{2}$ emission. Hugo and Pistikopoulos (2005) presented a biobjective mathematical programming model to consist environmental impact in forward supply chain network problem. The proposed model maximized the total profit and moreover, minimized the environmental impact by applying LCA principles. For electronic equipment recycling network, a model was presented by Quariguasi Frota Neto et al. (2009) to minimize traditional cost objective in addition to cumulative energy demand and wastes.

Quariguasi Frota Neto et al. (2008) proposed a bi-objective linear programming model for forward supply chain network design considering environmental impacts in European pulp and paper industry. However, the developed model is able to optimize the quantity of flow between supply chain layers and ignores the other decisions such as determining the location, number of facilities and capacity of them. All of the mentioned papers in the area of environmental supply chain network design avoid the integrated design of forward and reverse networks and incorporating the environmental issues into decision making model. In addition, all of the above mentioned papers are incapable to model the uncertainty of parameters in supply chain network design problem.

To cope the literature gap, this research work proposes a practical bi-objective fuzzy mathematical programming model for green supply chain network design problem that is able (1) based on decision maker's opinion, optimize both traditional cost and environmental objectives in the design of the logistic network, (2) integrate the design of forward and reverse supply chain networks, (3) handle the uncertainty of parameters caused by incompleteness or unavailability and imprecise nature of parameters. As it is mentioned in literature review, there is no paper, which takes environmental issues and economic costs into account simultaneously and can be based on real hypotheses and the expansion of parameters under uncertainty. The main contributions of this research work that differentiate this work from the related existing ones in the literature; can be summarized as follows:

- Proposing an efficient and realistic new supply chain network design model that designs both forward and reverse supply chains simultaneously moreover integrates the strategic decisions with tactical decisions in the context of closed loop supply chain that consider environmental impacts in shipment.

- To the best of our knowledge it is the first work that designs a general ( for example multi period and multi product) and realistic closed loop supply chain network considering environmental impact in shipment activities and additionally integrates strategic decision process and tactical levels.

Briefly, this work presented a general and practical bi-objective possibilistic model for integrating forward network and reverse supply chain network and design the whole supply chain network environmentally that is able to: (1) integrate the design of forward and reverse network in supply chains, (2) integrate strategic decision level such as facility location and with tactical decision like material flow ones at each period,(3) allow to appropriate trade-off between two important objectives function, the total costs and total $\mathrm{CO}_{2}$ emission (as an important environment factors) through the shipment in forward and reverse supply chain.

The organization of this paper is then as follows. In section 2 the problem is defined, in the third section the solution method is introduced, the forth section shows experimental results and sensitivity analyses and finally conclusion section deduces the previous sections and shows the advantage and performance of model. 


\section{The problem statement}

This section explains the characteristics and hypotheses of the model. As it is indicated in Fig. 1, goods produced in factory are transported to distribution centers to be distributed among customers. The probability of having defective goods from previous periods is greater than zero and these goods

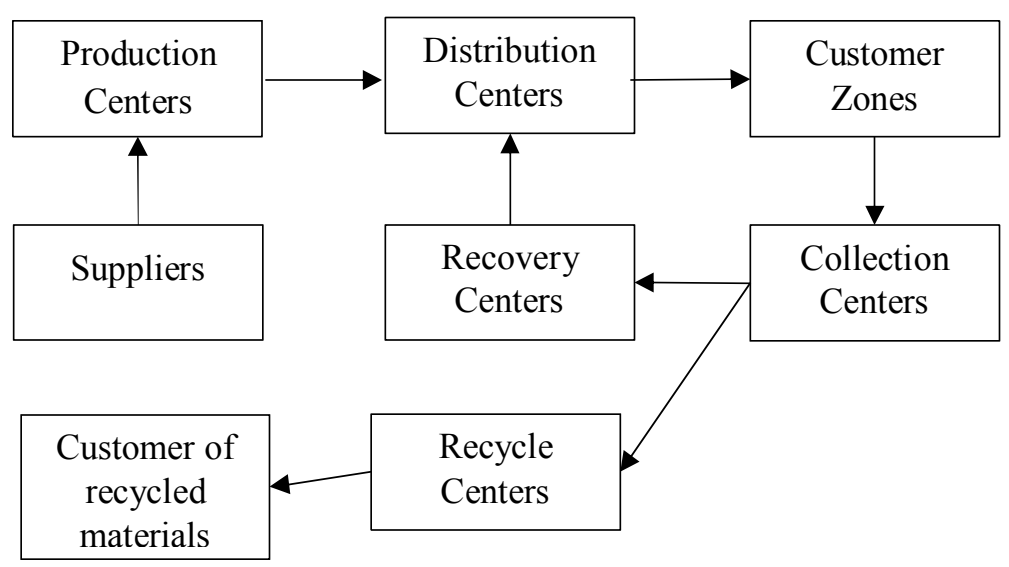

Fig. 1. Integrated supply chain

are sent to collection center to divide to two groups: recoverable goods, which return to distribution centers again, and the ones which must be recycled and convert to raw material so as to be sold. It is obvious, the factory capacity might be less than customers' demands and because of that, the needs of organization are met by suppliers. In other words, the required products are bought from suppliers and then they are transported to factory to be packed and sent to distribution centers. The operational risks is mentioned as the probability of defect. In the model the costs of facilities location, rates of $\mathrm{CO}_{2}$ emissions, available time of machines, the probabilities of defects and their costs, the rate of recoverability are consider uncertain and are put in the model in fuzzy form with the sign " $\sim$ " above them.

\subsection{Model assumption}

- The capacity of facilities (production center, suppliers, recovery center, and recycle center) are limited.

- The location of customer centers and the customers of recycled material are fixed.

- All demands must be satisfied.

- All potential locations of distribution centers, collection centers, recovery and recycle centers are discrete.

- There are no capacity constraints in transportation systems.

- Model is multi-period and multi-products.

- The amount of $\mathrm{CO}_{2}$ emissions are fuzzy.

- The probability of defect in products is greater than zero.

- The number of facilities which must be constructed are not determined.

- The number of recovery and recycle facilities which must be constructed are not determined.

\section{Indexes}

$i \quad$ Index of different suppliers $i=0,1, \ldots, I$

$j \quad$ Index of different parts, $j=0,1, \ldots, J$

$r \quad$ Index of candidate locations for the distribution centers, $r=0,1, \ldots, R$

$v \quad$ Index of fixed locations for the material costumer zones, $v=1,2, \ldots, V$

$k \quad$ Index of fixed locations for the costumer zones, $k=1,2, \ldots, K$ 
$q$ Index of candidate locations for the collection centers, $q=1,2, \ldots, Q$

$m \quad$ Index of candidate locations for the recovery centers, $m=1,2, \ldots, M$

$n \quad$ Index of candidate locations for the recycle centers, $n=1,2, \ldots, \mathrm{N}$

$z \quad$ Index of capacity levels available for distribution centers, $z=1,2, \ldots, Z$

$p \quad$ Index of mode of transportations $p=1,2, \ldots, \mathrm{P}$

$t \quad$ Index of time $t=1,2, \ldots, T$

\section{Parameters}

$\tilde{H}_{r}^{z} \quad$ Fixed cost of opening distribution center $r$ with capacity level $z$

$\tilde{h}_{q} \quad$ Fixed cost of opening collection center $q$

$\tilde{r}_{m} \quad$ Fixed cost of opening recovery center $m$

$\tilde{f_{n}} \quad$ Fixed cost of opening recycle center $n$

Cs Purchasing cost per machine

$C s_{m} \quad$ Purchasing cost per machine at recovery center $m$

$C s_{n} \quad$ Purchasing cost per machine at recycle center $n$

$\tilde{h}_{j} \quad$ Producing cost per unit $j$

$\tilde{\rho}_{j m} \quad$ Remanufacturing cost per unit $j$ at recovery center $m$

$\tilde{\tau}_{j n} \quad$ Recycling cost per unit $j$ at recycle center $n$

$\tilde{T}_{j i}^{p} \quad$ Transportation cost of one product unit $j$ from supplier $i$ to production center with mode $p$

$\tilde{c}_{j r}^{p} \quad$ Transportation cost of one product unit $j$ from production center to distribution center $r$ with mode $p$

$\tilde{a}_{j k}^{p} \quad$ Transportation cost of one product unit $j$ from distribution center $r$ to costumer zone $k$ with transportation mode $p$

$\tilde{b}_{j k q}^{p} \quad$ Transportation cost of one product unit $j$ of returned products from customer zone $k$ to collection center $q$ with transportation mode $p$

$\tilde{v}_{j q m}^{p} \quad$ Transportation cost of one product unit $j$ of recoverable products from collection center $q$ to recovery center $m$ with transportation mode $p$

$\tilde{s}_{j m r}^{p} \quad$ Transportation cost of one product unit $j$ of recovered products from recovery center $m$ to distribution center $r$ with transportation mode $p$

$\tilde{w}_{j q n}^{p} \quad$ Transportation cost of one product unit $j$ of recyclable products from collection center $q$ to recycle center $n$ with transportation mode $p$

$\tilde{V_{n v}^{p}} \quad$ Transportation cost of one raw material unit from recycle center $n$ to customer of recycled material $v$ with transportation mode $p$

$T \tilde{i} \quad$ Available time for one machine in production center (plant)

$\tilde{t}_{j} \quad$ Time needed for producing one product unit $j$

$T \tilde{M} \quad$ Available time for one machine in recovery center

$P \tilde{I} M_{j} \quad$ Time needed for recovering one product unit $j$ in recovery center

$T \tilde{N} \quad$ Available time for one machine in recycle center

$\tilde{P I N}_{j} \quad$ Time needed for recycling one product unit $j$ in recovery center

$\tilde{C}_{j i} \quad$ Capacity of supplier $i$ for producing part $j$ 
$V o R_{r}^{z} \quad$ Available volume for keeping parts of distribution center $r$ with capacity level $z$

$\tilde{t}_{j i}^{p} \quad$ Rate of $\mathrm{CO}_{2}$ emissions of transporting one unit $j$ from supplier $i$ to plant with mode $p$

$\tilde{\phi}_{j r}^{p} \quad$ Rate of $\mathrm{CO}_{2}$ emissions of transporting one unit $j$ from plant to distribution center $r$ with mode $p$

$\tilde{J}_{j r k}^{p} \quad$ Rate of $\mathrm{CO}_{2}$ emissions of transporting one unit $j$ from distribution center $r$ to customer $k$ with mode $p$

$\tilde{\vartheta}_{j k q}^{p} \quad$ Rate of $\mathrm{CO}_{2}$ emissions of transporting one unit $j$ from customer $k$ to collection center $q$ with mode $p$

$\tilde{\gamma}_{j q m}^{p} \quad$ Rate of $\mathrm{CO}_{2}$ emissions of transporting one unit $j$ from collection center $q$ to recovery center $m$ with mode $p$

$\tilde{\psi}_{j q n}^{p} \quad$ Rate of $\mathrm{CO}_{2}$ emissions of transporting one unit $j$ from collection center $q$ to recycle center $n$ with mode $p$

$\tilde{\pi}_{j m r}^{p} \quad$ Rate of $\mathrm{CO}_{2}$ emissions of transporting one unit $j$ from recovery center $m$ to distribution center $r$ with mode $p$

$\tilde{\partial}_{p w}^{p} \quad$ Rate of $\mathrm{CO}_{2}$ emissions of transporting one recycled unit from recycle center $n$ to raw customer of recycled material $v$ with mode $p$

$\tilde{q}_{j i} \quad$ Rate of defect of product $j$ from supplier $i$

$\tilde{\vartheta}_{j} \quad$ Rate of defect of product $j$ produced in production center

$\tilde{\omega}_{j k t} \quad$ Rate of return percentage product type $j$ from customer zone $k$ at the time $t$

$\tilde{r}_{j k t} \quad$ Amount of returned product unit $j$ to customer zone $k$ in period $t \quad\left(\tilde{r}_{j k t}=\tilde{\omega}_{j k t} \cdot \tilde{d}_{j k(t-1)}\right)$

$\tilde{\wp}_{j} \quad$ Rate of recoverable percentage product type $j$

$\mathrm{Fr}_{j} \quad$ The percent of raw material can take from product $j$

$\tilde{p}_{j i} \quad$ Price of buying of one unit of product $j$ from supplier $i$

$\tilde{e}_{j} \quad$ Per unit failure cost for the product $j$

$\tilde{C} o_{v} \quad$ Price per unit of raw material by customer of recycled material $v$

$\tilde{d}_{j k t} \quad$ Demand of costumer zone $k$ for product $j$ at period $t$

$V o_{j} \quad$ Volume of one unit of product $j$

\section{Decision variables}

$x_{j i t}^{p} \quad$ Quantity of parts $j$ shipped with mode $p$ from supplier $i$ to plant at period $t$

$y_{j n t}^{p} \quad$ Quantity of parts $j$ shipped with mode $p$ from plant to distribution center $r$ at period $t$

$\chi_{j r k t}^{p} \quad$ Quantity of part $j$ shipped with mode $p$ from distribution center $r$ to customer zone $k$ at period $t$

$\delta_{j k q t}^{p} \quad$ Quantity of returned products $j$ shipped with mode $p$ from customer zone $k$ to collection center $q$ at period $t$

$M_{j q m t}^{p} \quad$ Quantity of collected products $j$ shipped with mode $p$ from collection center $q$ to recovery center $m$ at period $t$ 


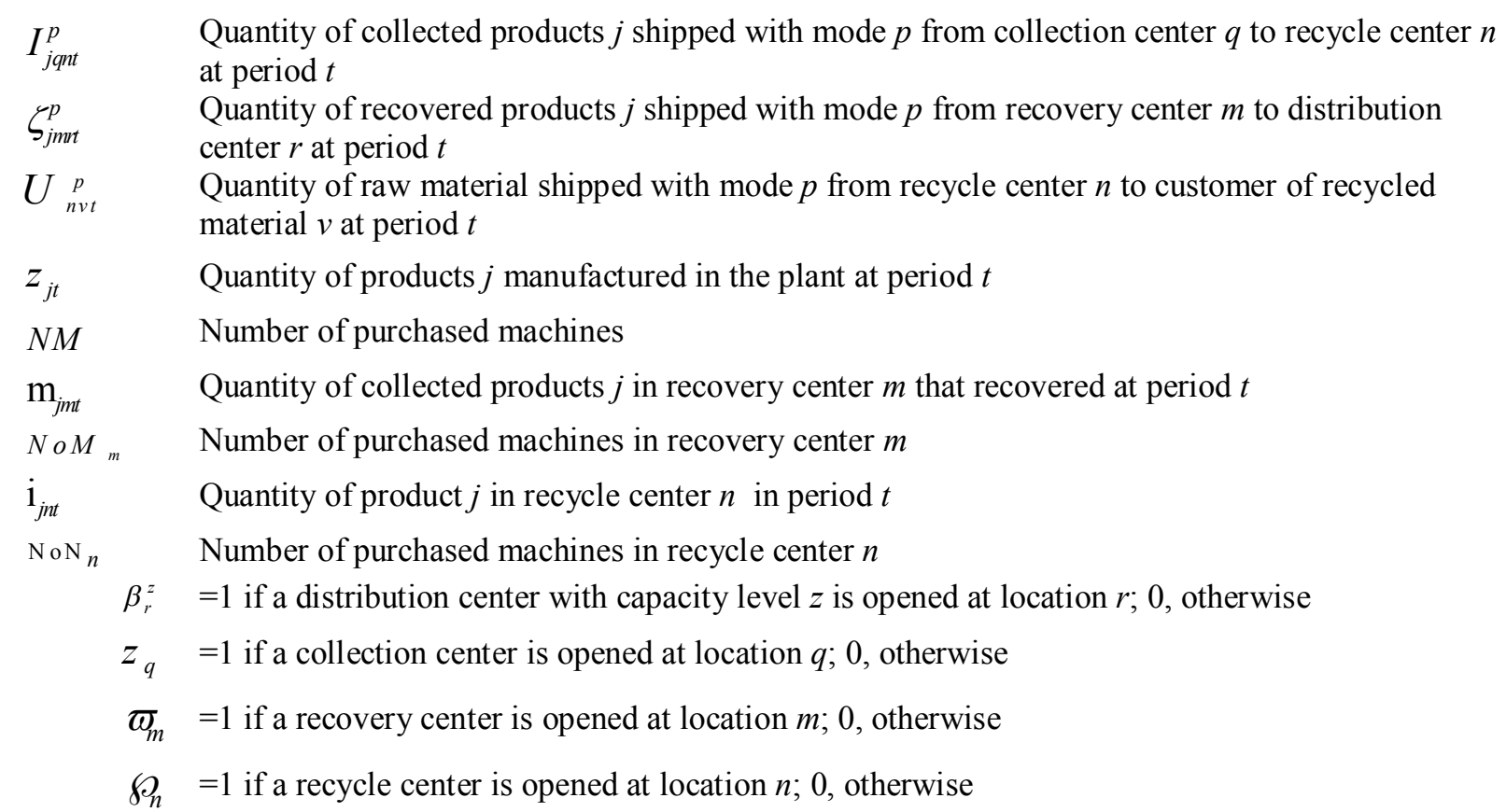

\subsection{Model formulation}

$$
\begin{aligned}
& \min \mathrm{Z}_{\mathrm{l}}=\sum_{i} \sum_{j} \sum_{p} \sum_{t} x_{j i t}^{p} \cdot \tilde{p}_{j i}+\sum_{i} \sum_{j} \sum_{p} \sum_{t} \tilde{q}_{j i} \cdot x_{j i t}^{p} \tilde{e}_{j}+\sum_{i} \sum_{j} \sum_{p} \sum_{t} x_{j i t}^{p} \tilde{T}_{j i}^{p}+\sum_{j} \sum_{t} z_{j t} \tilde{h}_{j}+N M \cdot C s \\
& +\sum_{j} \sum_{t} z_{j t} \cdot \tilde{\sigma}_{j} \cdot \tilde{e}_{j}+\sum_{r} \sum_{j} \sum_{p} \sum_{t} y_{v j t}^{p} \cdot \tilde{c}_{r j}^{p}+\sum_{r} \sum_{z} \tilde{H}_{r}^{z} \cdot \beta_{r}^{z}+\sum_{r} \sum_{k} \sum_{j} \sum_{p} \sum_{t} \chi_{j r k}^{p} \cdot \tilde{a}_{j r k}^{p}+\sum_{r} \sum_{k} \sum_{j} \sum_{p} \sum_{t} \delta_{j k q t}^{p} \tilde{b}_{j k q}^{p} \\
& +\sum_{q} \tilde{h}_{q} \cdot Z_{q}+\sum_{q} \sum_{j} \sum_{m} \sum_{p} \sum_{t} M_{j q m}^{p} \cdot \tilde{v}_{j q m}^{p}+\sum_{q} \sum_{n} \sum_{j} \sum_{p} \sum_{t}^{p}{ }_{j q n t}^{p} \cdot \tilde{w}_{j q n}^{p}+\sum_{m} \tilde{r}_{m} \cdot \sigma_{m}+\sum_{m} \sum_{j} \sum_{t} \mathrm{~m}_{j m t} \cdot \tilde{\rho}_{j m}+\sum_{m} C s_{m} \cdot N o M_{m} \\
& +\sum_{m} \sum_{r} \sum_{j} \sum_{p} \sum_{t} \zeta_{j m r t}^{q} \cdot \tilde{s}_{j m r}^{p}+\sum_{n} \sum_{v} \sum_{p} \sum_{t} U_{n v t}^{p} \cdot \tilde{V}_{n v}^{p}+\sum_{n} \tilde{f}_{n} \cdot \wp_{n}+\sum_{n} \sum_{j} \sum_{t} \mathrm{i}_{j n t} \cdot \tilde{\tau}_{j n}+\sum_{n} C s_{n} \cdot \mathrm{NoN}_{n}-\sum_{n} \sum_{v} \sum_{p} \sum_{t} U_{n v t}^{p} \cdot C \tilde{o}_{v}
\end{aligned}
$$

$$
\begin{aligned}
& \min \mathrm{Z}_{2}=\sum_{i} \sum_{j} \sum_{p} \sum_{t} x_{j i t}^{p} \tilde{t}_{j i}^{p}+\sum_{r} \sum_{j} \sum_{p} \sum_{t} y_{j r t}^{p} \cdot \tilde{\phi}_{j r}^{p}+\sum_{r} \sum_{k} \sum_{j} \sum_{p} \sum_{t} \chi_{j r k t}^{p} \cdot \tilde{J}_{j r k}^{p}+\sum_{k} \sum_{q} \sum_{j} \sum_{p} \sum_{t} \delta_{j k q t}^{p} \cdot \tilde{\vartheta}_{j k q}^{p} \\
& \quad+\sum_{q} \sum_{m} \sum_{j} \sum_{p} \sum_{t} M_{j q m t}^{p} \cdot \tilde{\gamma}_{j q m}^{p}+\sum_{q} \sum_{n} \sum_{j} \sum_{p} \sum_{t} I_{j q n t}^{p} . \tilde{\psi}_{j q n}^{p}+\sum_{m} \sum_{r} \sum_{j} \sum_{p} \sum_{t} \zeta_{j m r t}^{p} \cdot \tilde{\pi}_{j m r}^{p}+\sum_{n} \sum_{v} \sum_{p} \sum_{t} U_{n v t}^{p} \tilde{\partial}_{n v}^{p}
\end{aligned}
$$

\section{Subject to:}

$$
\begin{aligned}
& \sum_{p} X_{j i t}^{p} \leq \tilde{C}_{j i}, \quad \forall i, j, t \\
& \sum_{r} \sum_{p} \chi_{j r k t}^{p} \geq \tilde{d}_{j k t}, \quad \forall j, t, k \\
& \sum_{j} Z_{j t} \cdot P \tilde{t}_{j} \leq N M T \tilde{i}, \quad \forall t \\
& \sum_{i} \sum_{p} x_{j i t}^{p}+z_{j t}=\sum_{r} \sum_{p} \mathrm{y}_{j r t}^{p}, \quad \forall j, t
\end{aligned}
$$




$$
\begin{aligned}
& \sum_{p} \mathrm{y}_{j r t}^{p}+\sum_{m} \sum_{p} \zeta_{j m i t}^{p}=\sum_{k} \sum_{p} \chi_{j r k t}^{p}, \quad \forall r, j, t \\
& \sum_{q} \sum_{p} \delta_{j k q t}^{p} \geq \tilde{r}_{j k t}\left(=\tilde{\omega}_{j k t} \tilde{d}_{j k(t-1)}\right), \quad \forall k, j, t \\
& \sum_{k} \sum_{p} \delta_{j k q t}^{p}=\sum_{m} \sum_{p} M_{j q m t}^{p}+\sum_{n} \sum_{p} I_{j q n t}^{p}, \quad \forall q, j, t \\
& \tilde{\wp}_{j} \cdot \sum_{k} \sum_{p} \delta_{j k q t}^{p}=\sum_{m} \sum_{p} M_{j q m t}^{p}, \quad \forall q, j, t \\
& \sum_{q} \sum_{p} M_{j q m t}^{p}=\sum_{r} \sum_{p} \zeta_{j m r t}^{p}, \quad \forall m, j, t \\
& m_{j m t}=\sum_{q} \sum_{p} M_{j q m t}^{p}, \quad \forall j, m, t \\
& \operatorname{Fr}_{j} \cdot \sum_{q} \sum_{p} I_{j q n t}^{p}=\sum_{v} \sum_{p} U_{n v t}^{p}, \quad \forall n, j, t \\
& i_{j n t}=\sum_{q} \sum_{p} I_{j q n t}^{p}, \quad \forall j, t, n \\
& \sum_{j}\left[\left(\sum_{k} \sum_{p} \chi_{j r k t}^{p}\right) V o_{j}\right] \leq \sum_{z} V o R_{r}^{z} \cdot \beta_{r}^{z}, \quad \forall r, t \\
& \sum_{j} m_{j m t} \cdot P \tilde{T M_{j}} \leq T \tilde{M} \cdot N o M_{m}, \quad \forall m, t \\
& \sum_{j} i_{j n t} P \tilde{T N}_{j} \leq T \tilde{N} \operatorname{NoN}_{n}, \quad \forall n, t \\
& \sum_{z} \beta_{r}^{z} \leq 1, \forall r \\
& \sum_{k} \sum_{j} \sum_{p} \sum_{t} \delta_{j k q t}^{p} \leq M . z_{q}, \quad \forall q \\
& \sum_{q} \sum_{j} \sum_{p} \sum_{t} M_{j q m t}^{p}+N o M_{m} \leq M . \varpi_{m}, \quad \forall m \\
& \sum_{q} \sum_{j} \sum_{p} \sum_{t} I_{j q n t}^{p}+\sum_{j} \sum_{s} \sum_{t} \mathrm{i}_{j n t}^{s} \leq M . \wp_{n}, \quad \forall n \\
& \beta_{r}^{z}, z_{q}, \varpi_{m}, \wp_{n} \in\{0,1\}, \quad \forall r, z, q, m, n, \\
& x_{j i t}^{p}, y_{j i t}^{p}, \chi_{j k t t}^{p}, \delta_{j k q t}^{p}, M_{j q m t}^{p}, I_{j q n t}^{p}, \zeta_{j m m t}^{p} \in Z^{+}, \quad \forall p, j, i, t, r, k, q, m, n, \\
& U_{n v t}^{p} \geq 0, \quad \forall p, n, v, t, \\
& z_{j t}, N M, \mathrm{~m}_{j m t}, N o M_{m}, \mathrm{i}_{j n t}, \mathrm{NoN}_{n} \in Z^{+}, \quad \forall j, t, m, n .
\end{aligned}
$$

The first objective function minimizes economic costs. (buying from suppliers, the cost of defective product bought from suppliers, transportation costs, facilities location costs in production centers, recovery centers, recycle center), costs of purchasing machines). The second function minimizes the amount of $\mathrm{CO}_{2}$ emissions. Constraint (1) ensures that the demands of organization for goods are less than suppliers' capacity. Constraints (2) meet the customers' demands. Constraint (3) assures the production of factory is less than its capacity. Constraints (4-9) and (11) respectively strike balances between inputs and outputs in production centers, distribution centers, collection, recovery, and recycle centers. Constraints (10) and (12) ensure the demands in recovery and recycle centers are met completely. Constraints (13-15) assure that the limitation of capacities of recovery centers, recycle centers, and stores are considered. Constraint (16) assures if a distribution center founded it has just one type of capacity. Constraints (17-19) make sure that no good is sent to any collection center, recovery center, or recycle center unless they are founded. 


\section{Solution procedure}

The first step: a definite crisp auxiliary multi objective model for the fuzzy model:

In literature review, for solving fuzzy models, there are several ways to face to solve them (Jimenez, 1996; Wang \& Liang; 2005; Parra et al., 2005) the method used in this paper has two stage the first one crisp auxiliary multi objective. What makes this model useful is its applicability on stochastic parameters with different fuzzy functions whether they are symmetric or not.

The concepts such as expected interval and expected value are the critical parameters of this method. First, these concepts were introduced by Yager (1981). For the introduction of these concepts triangle fuzzy number $\tilde{c}=\left(c^{p}, c^{m}, c^{o}\right)$ is considered and its membership function is explained as follow:

$$
\mu_{\tilde{c}}(x)= \begin{cases}f_{\mathcal{C}}(x)=\frac{x-c^{p}}{c^{m}-c^{p}} & \text { if } c^{p} \leq x \leq c^{m} \\ 1 & \text { if } x=c^{m} \\ g_{c}(x)=\frac{c^{o}-x}{c^{o}-c^{m}} & \text { if } c^{m} \leq x \leq c^{o} \\ 0 & \text { if } x \leq c^{p} \text { or } x \geq c^{o}\end{cases}
$$

Expected interval (EI) and expected value (EV) for the triangle fuzzy number $\tilde{c}$ are as follow:

$$
\begin{aligned}
& E I(\tilde{c})=\left[E_{1}^{c}, E_{2}^{c}\right]=\left[\int_{0}^{1} f_{c}^{-1}(x) d x, \int_{0}^{1} g_{c}^{-1}(x) d x\right]=\left[\frac{1}{2}\left(c^{p}+c^{m}\right), \frac{1}{2}\left(c^{m}+c^{o}\right)\right] \\
& E V(\tilde{c})=\frac{E_{1}^{c}+E_{2}^{c}}{2}=\frac{c^{p}+2 c^{m}+c^{o}}{4}
\end{aligned}
$$

Apart from that, for each pair fuzzy number $\tilde{a}$ and $\tilde{b}$ the degree of $\tilde{a}$ which is greater than $\tilde{b}$ is:

$$
\mu_{M}(\tilde{a}, \tilde{b})=\left\{\begin{array}{lll}
0 & \text { if } \quad E_{2}^{a}-E_{1}^{b} \prec 0 \\
\frac{E_{2}^{a}-E_{1}^{b}}{E_{2}^{a}-E_{1}^{b}-\left(E_{1}^{a}-E_{2}^{b}\right)} & \text { if } \quad E_{1}^{a}-E_{2}^{b} \prec 0 \prec E_{2}^{a}-E_{1}^{b} \\
1 & \text { if } \quad E_{1}^{a}-E_{2}^{b} \succ 0
\end{array}\right.
$$

$\mu_{M}(\tilde{a}, \tilde{b})$ Indicates the degree of $\tilde{a}$ which is greater than $\tilde{b}$. When it is said $\mu_{M}(\tilde{a}, \tilde{b}) \geq \alpha$ it means $\tilde{a}$ is at least greater than $\tilde{b}$ with $\alpha$ degree and it is shown as $\tilde{a} \geq_{\alpha} \tilde{b}$. Apart from that, for each pair fuzzy number $\tilde{a}$ and $\tilde{b}$ it is said $\tilde{a}$ is equal to $\tilde{b}$ with $\alpha$ degree if these two formulas are exist simultaneously:

$\tilde{a} \geq_{\alpha / 2} \tilde{b} \quad, \quad \tilde{a} \leq_{\alpha / 2} \tilde{b}$

and

$$
\frac{\alpha}{2} \leq \mu_{M}(\tilde{a}, \tilde{b}) \leq 1-\frac{\alpha}{2}
$$

Now, if we consider a fuzzy mathematical programming model in which all parameters are defined as triangular fuzzy numbers. Based on mentioned explanation objective functions and constraints (1), (2), (3), (6), 
(8) (this constraint is divided into two constraints), (14), (15) convert to (1'), (2'), (3'), (6'), (8'), (8’), (14'), (15'). This method turns fuzzy model to auxiliary crisp model.

\subsection{Auxiliary Crisp Model}

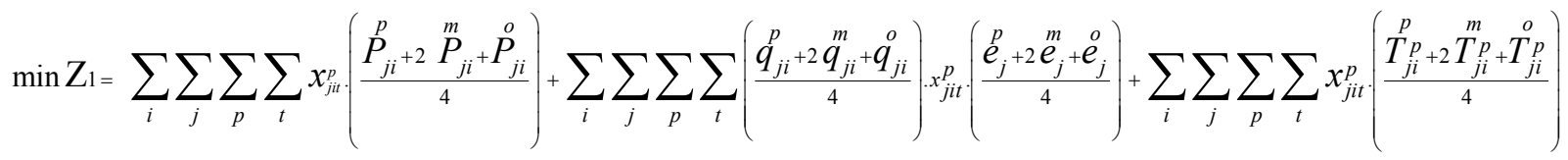

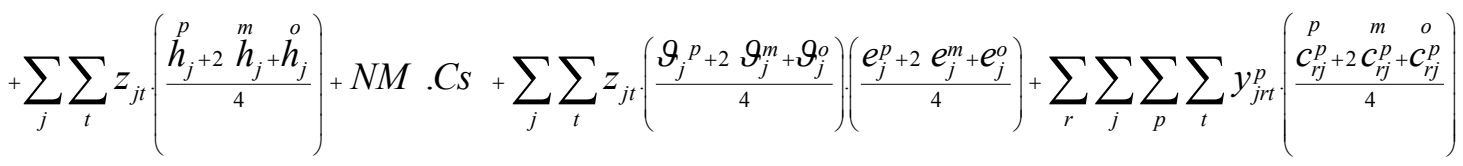

$$
\begin{aligned}
& +\sum_{r} \sum_{z}\left(\frac{\stackrel{p}{H_{r}^{z}+2} \stackrel{m}{H_{r}^{z}}+\stackrel{o}{H_{r}^{z}}}{4}\right) \beta_{r}^{z}+\sum_{r} \sum_{k} \sum_{j} \sum_{p} \sum_{t} \chi_{j r k t}^{p}\left(\frac{\begin{array}{cc}
p & m \\
a_{j r k}^{p}+2 & \stackrel{o}{a_{j r k}^{p}}+a_{j r k}^{p}
\end{array}}{4}\right)+\sum_{k} \sum_{q} \sum_{j} \sum_{p} \sum_{t} \delta_{j k q t}^{p}\left(\frac{\begin{array}{c}
p \\
b_{j k q}^{p}+2 b_{j k q}^{p}+b_{j k q}^{p}
\end{array}}{4}\right)
\end{aligned}
$$

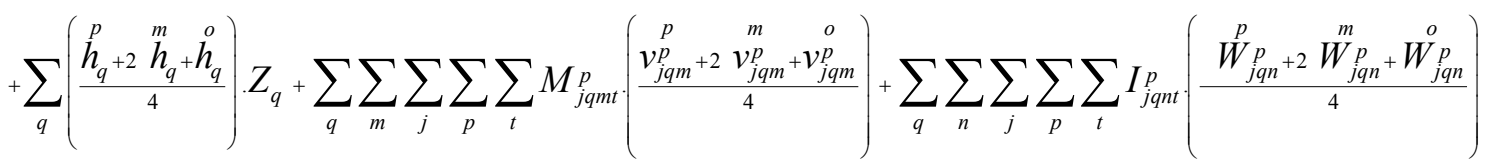

$$
\begin{aligned}
& +\sum_{m}\left(\frac{p_{m}^{p}+2 r_{m}^{m}+r_{m}^{o}}{4}\right) \cdot \varpi_{m}+\sum_{m} \sum_{j} \sum_{t} \mathrm{~m}_{j m t}\left(\frac{\stackrel{p}{\rho}_{j m+2}{\stackrel{m}{\rho_{j m}}+\rho_{j m}^{o}}^{\prime}}{4}\right)+\sum_{m} C S_{m} \cdot N o M_{m}+\sum_{m} \sum_{r} \sum_{j} \sum_{p} \sum_{t} \zeta_{j m r t}^{p} \cdot\left(\frac{S_{j m r}^{p}+2 \stackrel{p}{S_{j m r}^{p}}+S_{j m r}^{p}}{4}\right) \\
& +\sum_{n} \sum_{v} \sum_{p} \sum_{t} U_{n v t}^{p} \cdot\left(\frac{\stackrel{p}{V_{n v}^{p}} \stackrel{p}{V_{n v}^{p}}+\stackrel{p}{V_{n v}^{p}}}{4}\right)+\sum_{n}\left(\frac{f_{n}^{p}+2 f_{n}^{m}+f_{n}^{o}}{4}\right) \cdot \wp_{n}+\sum_{n} \sum_{j} \sum_{t} \mathrm{i}_{j n t} \cdot\left(\frac{\stackrel{p}{\tau_{j n}+2} \stackrel{m}{\tau_{j n}+\tau_{j n}^{o}}}{4}\right)+\sum_{n} C S_{n} \cdot \mathrm{NoN}_{n} \\
& -\sum_{n} \sum_{v} \sum_{p} \sum_{t} \sum_{t} U_{n v t}^{p}\left(\frac{\left.\stackrel{p}{C o_{v}+2} \stackrel{m}{C_{v}}+\stackrel{o}{C o}\right)}{4}\right)
\end{aligned}
$$

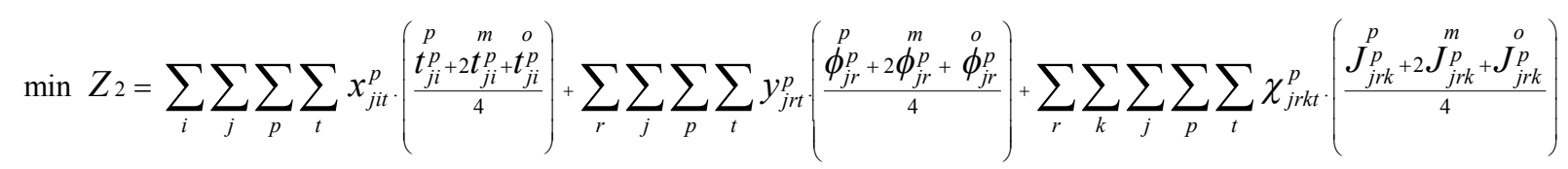

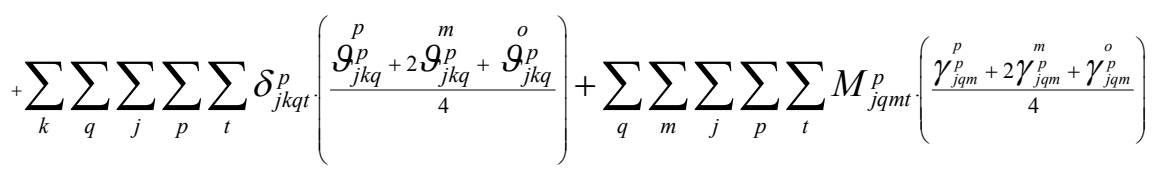

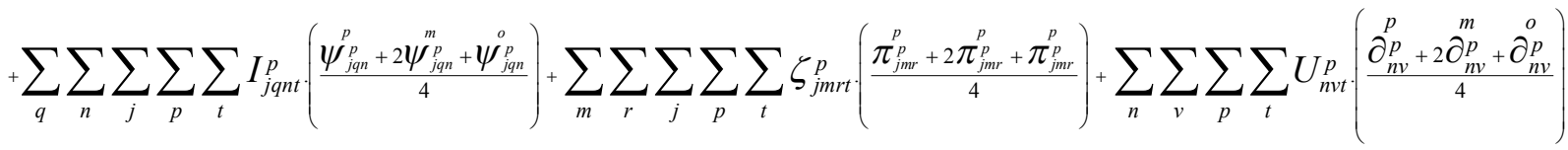

subject to

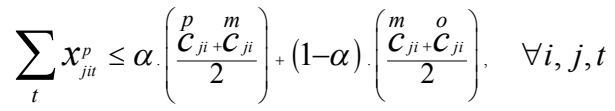

$$
\begin{aligned}
& \sum_{r} \sum_{p} \chi_{j r k t}^{p} \geq \alpha \cdot\left(\frac{d_{j k t}+d_{j k t}}{2}\right)+(1-\alpha) \cdot\left(\frac{d_{j k t}^{p}+d_{j k t}^{m}}{2}\right), \forall j, t, k \\
& {\left[\frac{\alpha}{2} \cdot\left(\frac{\wp_{j}+\wp_{j}}{2}\right)+\left(1-\frac{\alpha}{2}\right) \cdot\left(\frac{\wp_{j}^{p}+\stackrel{m}{\wp}_{j}}{2}\right)\right] \cdot \sum_{k} \sum_{p} \delta_{j k q t}^{p} \leq \sum_{m} \sum_{p} M_{j q m t}^{p} \quad \forall q, j, t}
\end{aligned}
$$


$\sum_{t} \delta_{j k q t}^{p} \geq \alpha \cdot\left(\frac{r_{j k t}^{m}+r_{j k t}^{o}}{2}\right)+(1-\alpha) \cdot\left(\frac{r_{j k t}^{p}+r_{j k t}^{m}}{2}\right), \quad \forall k, j, t$

$\left[\frac{\alpha}{2} \cdot\left(\frac{\wp_{j}+\stackrel{o}{\wp}_{j}}{2}\right)+\left(1-\frac{\alpha}{2}\right) \cdot\left(\frac{\wp_{j}^{p}+\stackrel{m}{\wp}_{j}}{2}\right)\right] \cdot \sum_{k} \sum_{p} \delta_{j k q t}^{p} \leq \sum_{m} \sum_{p} M_{j q m t}^{p} \forall q, j, t$

$\left[\left(1-\frac{\alpha}{2}\right) \cdot\left(\frac{\stackrel{m}{\wp}_{j}+\stackrel{o}{\wp}_{j}}{2}\right)+\frac{\alpha}{2} \cdot\left(\frac{\stackrel{p}{\wp}_{j}+\stackrel{m}{\wp}_{j}}{2}\right)\right] \cdot \sum_{k} \sum_{p} \delta_{j k q t}^{p} \geq \sum_{m} \sum_{p} M_{j q m t}^{p} \forall q, j, t$

$\left.\sum_{j} m_{j m t} \cdot\left[\alpha \cdot\left(\frac{P M^{m} M_{j}+P \stackrel{o}{T} M_{j}}{2}\right)+(1-\alpha) \cdot\left(\frac{P P^{p} M_{j}+P M_{j}}{2}\right)\right] \leq \alpha \cdot\left(\frac{T^{p} M_{+} T M}{2}\right)+(1-\alpha) \cdot\left(\frac{m M^{m}+T \stackrel{o}{2}}{2}\right)\right] \cdot N o M_{n} \quad \forall n, t$

$\left.\sum_{j} i_{j n t} \cdot\left[\alpha \cdot\left(\frac{P{ }^{m} N_{j}+P N^{o}}{j}\right)+(1-\alpha) \cdot\left(\frac{P T^{p} N_{j}+P N^{m}}{2}\right)\right] \leq \alpha \cdot\left(\frac{T^{p} N^{+T N}}{2}\right)+(1-\alpha) \cdot\left(\frac{T N^{m}+T \stackrel{o}{T}}{2}\right)\right] \cdot N o N_{n} \quad \forall n, s, t$

\subsection{The second step: Torabi-Hasini (TH)}

In this step, the solving method is a combined method of Torabi-Hasini (TH) method (Torabi and Hassini (2008) and Jimenez (Jimenez (1996)). The steps of the applied hybrid method can be summarized as follows:

Step 1: Determine the appropriate triangular possibility distributions for imprecise coefficients and formulate the multi objective model,

Step 2: Convert the objective functions into the crisp model so as to use the expected value of corresponding imprecise parameters,

Step 3: Calculate the minimum acceptable feasibility degree of decision vector and convert the fuzzy constraints into the crisp constraints, and formulate the equivalent auxiliary crisp multi objective model,

Step 4: Calculate the $\alpha$-positive optimal solution ( $\alpha$-PIS) and $\alpha$-negative optimal solution ( $\alpha$-NIS) for each objective function,

Step5: Calculate a linear membership function for each objective function:

$$
\begin{aligned}
& \mu_{1}(x)= \begin{cases}1 & \text { if } Z_{1}^{\alpha-P I S} \leq Z_{1} \\
\frac{Z_{1}-Z_{1}^{\alpha-N I S}}{Z_{1}^{\alpha-P I S}-Z_{1}^{\alpha-N I S}} & \text { if } Z_{1}^{\alpha-N I S} \leq Z_{1} \leq Z_{1}^{\alpha-P I S} \\
0 & \text { if } Z_{1} \leq Z_{1}^{\alpha-N I S}\end{cases} \\
& \mu_{2}(x)=\left\{\begin{array}{lll}
1 & \text { if } Z_{2}^{\alpha-P I S} \leq Z_{2} \\
\frac{Z_{2}-Z_{2}^{\alpha-N I S}}{Z_{2}^{\alpha-P I S}-Z_{2}^{\alpha-N I S}} & \text { if } Z_{2}^{\alpha-N I S} \leq Z_{2} \leq Z_{2}^{\alpha-P I S} \\
0 & \text { if } Z_{2} \leq Z_{2}^{\alpha-N I S}
\end{array}\right.
\end{aligned}
$$

where $\mu_{h}(x)$ means the satisfaction degree of $h^{\text {th }}$ objective function. 
Step 6: Convert the crisp auxiliary multi objective model into a single objective model using TorabiHasini (TH) method (Torabi \& Hassini, 2008). The TH aggregation function is as follows:

subject to

$$
\begin{aligned}
& \lambda_{0} \leq \mu_{h}(x), \quad h=1,2 \\
& x \in F(x) \\
& \lambda_{0}, \lambda \in[0,1] \\
& \min \lambda(x)=\gamma \lambda_{h}+(1-\gamma) \sum_{h} \theta_{h} \cdot \mu_{h}(x)
\end{aligned}
$$

where $\mathrm{F}(\mathrm{x})$ indicate the feasible region involving the constraints of equivalent crisp model. In addition, $\theta_{h}$ and $\gamma$ respectively indicate the importance of the $h$ th objective function and the coefficient of compensation.,

Step 7: Determine the $\gamma$ (value of the coefficient of compensation) and relative $\theta_{h}$ (importance of the fuzzy goals), and solve the single objective mixed integer linear programming model. If the current solution accepted by decision makers, stop, otherwise prepare another compromise solution by changing the value of $\gamma, \alpha$ and $\theta_{h}$ then go to step 3 .

\section{Experimental results}

To prove the validity of the model several numerical experiments are executed and relevant solution results are indicated in this section. For obtaining solution results, GAMS software is used and are shown in Table 1. The data of the model has been derived, and simulated from the data of papers reviewed in literature review (Pishvaee \& Shakouri, 2009; Pishvaee \& Torabi, 2010).

Table 1

Experimental results obtained by GAMS software

\begin{tabular}{ccccccc}
\hline \multirow{2}{*}{ Least possibility degree } & \multicolumn{2}{c}{ Importance degree of objective function } & \multicolumn{2}{c}{ Satisfaction level } & \multicolumn{2}{c}{ Objective Function } \\
\hline$\lambda$ & $v 1$ & $v 2$ & $\mu 1$ & $\mu 2$ & Cost $\left(\mathrm{Z}_{1}\right)$ & $\mathrm{CO}_{2}$ emission $\left(\mathrm{Z}_{2}\right)$ \\
\hline & 0.95 & 0.05 & 0.997 & 0.546 & 6989861435 & 2498152.964 \\
& 0.8 & 0.2 & 0.952 & 0.746 & 7139663542 & 2357456.65 \\
& 0.5 & 0.5 & 0.898 & 0.808 & 7323498057 & 2983678.466 \\
& 0.2 & 0.8 & 0.764 & 0.912 & 7697564789 & 2385177.55 \\
& 0.05 & 0.95 & 0.665 & 0.978 & 7948230467 & 22456789.88 \\
\hline & 0.95 & 0.05 & 0.977 & 0.576 & 6915280128 & 2421879.98 \\
& 0.8 & 0.2 & 0.942 & 0.746 & 7018082237 & 2379567.88 \\
& 0.5 & 0.5 & 0.838 & 0.826 & 7218916754 & 2320765.09 \\
& 0.2 & 0.8 & 0.778 & 0.913 & 7622567997 & 21467.965 \\
& 0.05 & 0.95 & 0.692 & 0.984 & 78436496675 & 2073525.96 \\
\hline & 0.9 & 0.05 & 0.986 & 0.504 & 615147968 & 2389876.65 \\
& 0.8 & 0.2 & 0.962 & 0.724 & 6917950087 & 2326019.98 \\
& 0.5 & 0.5 & 0.887 & 0.798 & 7118485733 & 2267386.98 \\
\hline & 0.2 & 0.8 & 0.791 & 0.912 & 7522854325 & 2186043.19 \\
\hline
\end{tabular}

To examine the reliability of the model and the solution method or on the other words, to examine the efficiency of them, the results are compared with the results of the model of (Pishvaee \& Torabi, 2010). By solving two models, it is concluded that the proposed model increases the economic costs by 18 percent. Some of the most important differences between two models are: 1) This paper consider environmental issues to strike a balance between economic costs and environmental ones which results in difference between the costs of two models. 2) The cost of giving defective goods to customers is considered in the proposed model. 3) The proposed model determines how many 
machines must be purchased for production centers, recovery centers, and recycle centers. However, the model of (Pishvaee \& Torabi, 2010) neglects these costs. Although in this model the income of selling recycled products is considered, the income is not enough to cover the increase occurred in costs.

As it is known supply chain network design problems are in the category of NP-Hard problems. Therefore, to solve the problem in large size, NSGA-II algorithm is applied.

\subsection{NSGA-II algorithm}

This algorithm is based on nondominated sorting. In this algorithm, $N$ is considered as the size of population. At first, a random population produced and then nondominated operations are applied on the population. These operation divided the population to different nondominated level. The set of nondominated members is called nondominated members of level 1. To each answer, on fitting based on its nondominated level, so minimizing the fitting is the goal. The crossover, mutation, competitive density choice operations help us create offspring population with the size of $N$. In competitive choice, the answer with less fitting value is the better one. In order to set the parameters of the algorithm the problem is divided into two categories the large sized problems and small sized problems and for each category, the best parameters are approximated. In this paper the response surfaces methodology (RSM) is applied. This method use regression equations to evaluate different response surfaces. RSM chooses some response surfaces as input parameters (for objective function) and then by fitting to the best regression equation best values for parameters of algorithm are chosen. Table 2 show the parameters obtained by RSM.

Table 2

Setting parameters for NSGA-II

\begin{tabular}{lcc}
\hline & Small size & Large size \\
\hline Number of population & 300 & 200 \\
\hline Mutation rate & \multicolumn{2}{c}{0.2} \\
Crossover rate & 100000 & 0.8 \\
\hline Num. of runs after which the algorithm stops & 30000 \\
\hline
\end{tabular}

There are 18 sets of parameters in medium and large size prepared and the answers are shown in Table 3. To compare the 18 data sets the index of spacing metric is used to decide on the best answer.

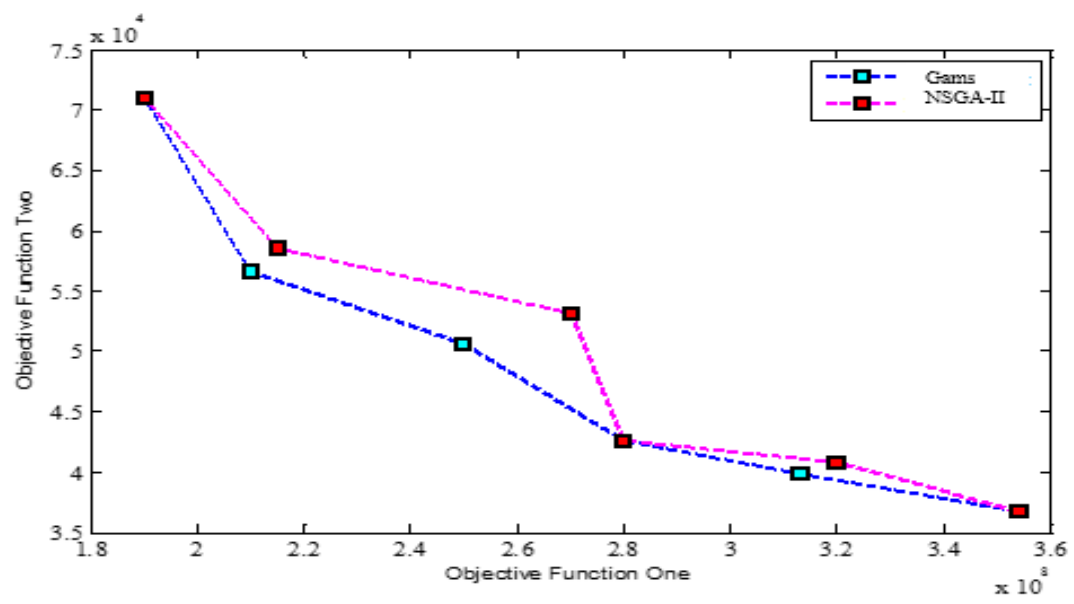

Fig. 2. Comparison between GAMS and NSGA-II performance

To examine the validity of NSGA-II performance 6 experimental experiments in small size are solved by GAMS and NSGA-II and the results are compared in Fig. 2. The figure shows NSGA-II works properly. 


\subsection{Spacing metric}

The index shows the uniformity of distribution of Pareto solution in the solution space calculated as follows:

$S M=\frac{\sum_{i=1}^{n-1}\left|\bar{d}-d_{i}\right|}{(n-1) \bar{d}}$

where $d_{i}$ is Euclidean distance between two adjacent Pareto solution in the solution space and also $\bar{d}$ is also equal to the mean distance. The less the spacing metric, the better the algorithm works.

Table 3

Experimental results by NSGA-II

\begin{tabular}{ccccc}
\hline Num. of problem & Average $\mathrm{CO}_{2}$ emissions & Average costs & SM & Alpha \\
\hline 1 & 7749233971 & 67884099119 & 0.727 & 0.7 \\
2 & 789326685 & 98630064856 & 0.744 & 0.8 \\
3 & 794729816 & 82640433316 & 0.791 & 0.9 \\
4 & 6513944608 & 81404498211 & 0.738 & 0.7 \\
5 & 84056478 & 76831383347 & 0.571 & 0.8 \\
6 & 8569120687 & 66521453991 & 0.499 & 0.9 \\
7 & 8815641726 & 63671110978 & 0.793 & 0.7 \\
1 & 97702965 & 59763243023 & 0.983 & 0.8 \\
1 & 9944657 & 44800707396 & 0.853 & 0.9 \\
11 & 1018981545 & 34077513029 & 1.101 & 0.7 \\
12 & 11065468 & 2113753011 & 1.311 & 0.8 \\
14 & 111617302 & 1193583067 & 0.945 & 0.9 \\
15 & 1137759498 & 9602657261 & 0.964 & 0.7 \\
17 & 1195609644 & 9858874472 & 0.731 & 0.8 \\
\end{tabular}

Fig. 3 indicates the Pareto solutions of the model and assures that the model works efficiently and effectively.

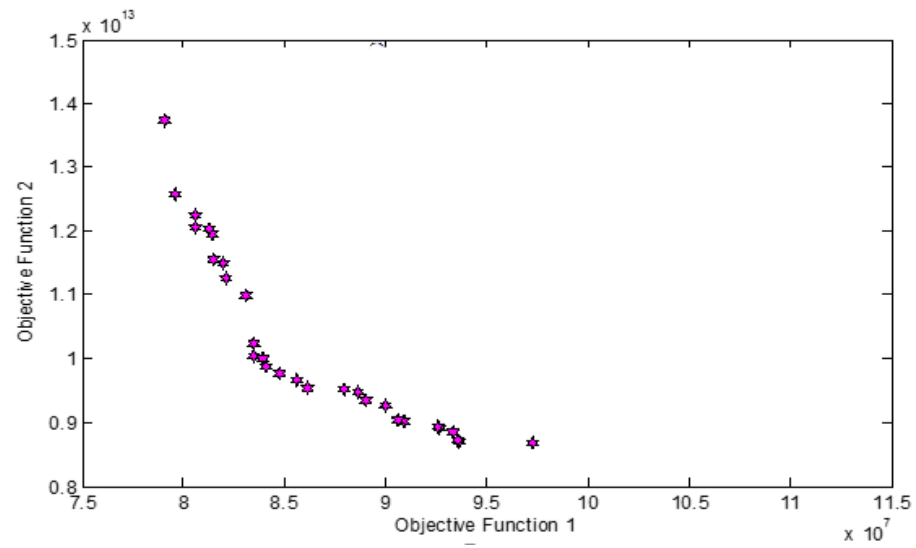

Fig. 3. The Pareto solution solved by NSGA-II

\section{Sensitivity analysis}

In this section the effect of changing the range of some parameters on objective functions are examined. 


\subsection{The effect of increasing the capacity of suppliers}

As it is shown in Fig. 4 and Fig. 5 by increasing the capacity of suppliers the first objective function increase because this work change the boundaries of feasible space and the maximum usage of supplier increases. Apart from that, because of the increase in transportation costs and the increase of the possibility of defective goods the cost function increase. Yet, the $\mathrm{CO}_{2}$ emissions amount decreases because of being independent of the amount of shipped goods and services. Table 4 shows the changes in two objective functions.

Table 4

The effect of changing suppliers capacities on two objective functions

\begin{tabular}{ccc}
\hline Suppliers capacity & Objective function 1 & Objective function 2 \\
\hline 3.161100495 & 5677083.6 & $1.12 \mathrm{E}+05$ \\
4.161100495 & 5762508.906 & $1.12 \mathrm{E}+05$ \\
5.161100495 & $5.85 \mathrm{E}+06$ & $1.12 \mathrm{E}+05$ \\
6.161100495 & 5933359.297 & $1.12 \mathrm{E}+05$ \\
7.161100495 & 6018784.547 & $1.12 \mathrm{E}+05$ \\
\hline
\end{tabular}

\section{First Objective Function}

6100000

6000000

5900000

5800000

5700000

5600000

5500000

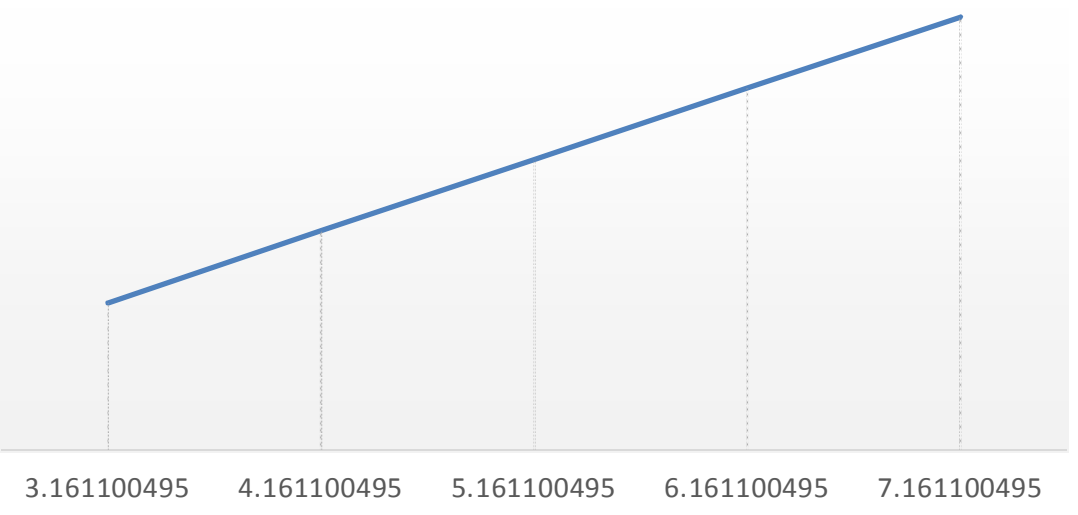

Fig. 4. The effect of changing suppliers capacities on first objective functions

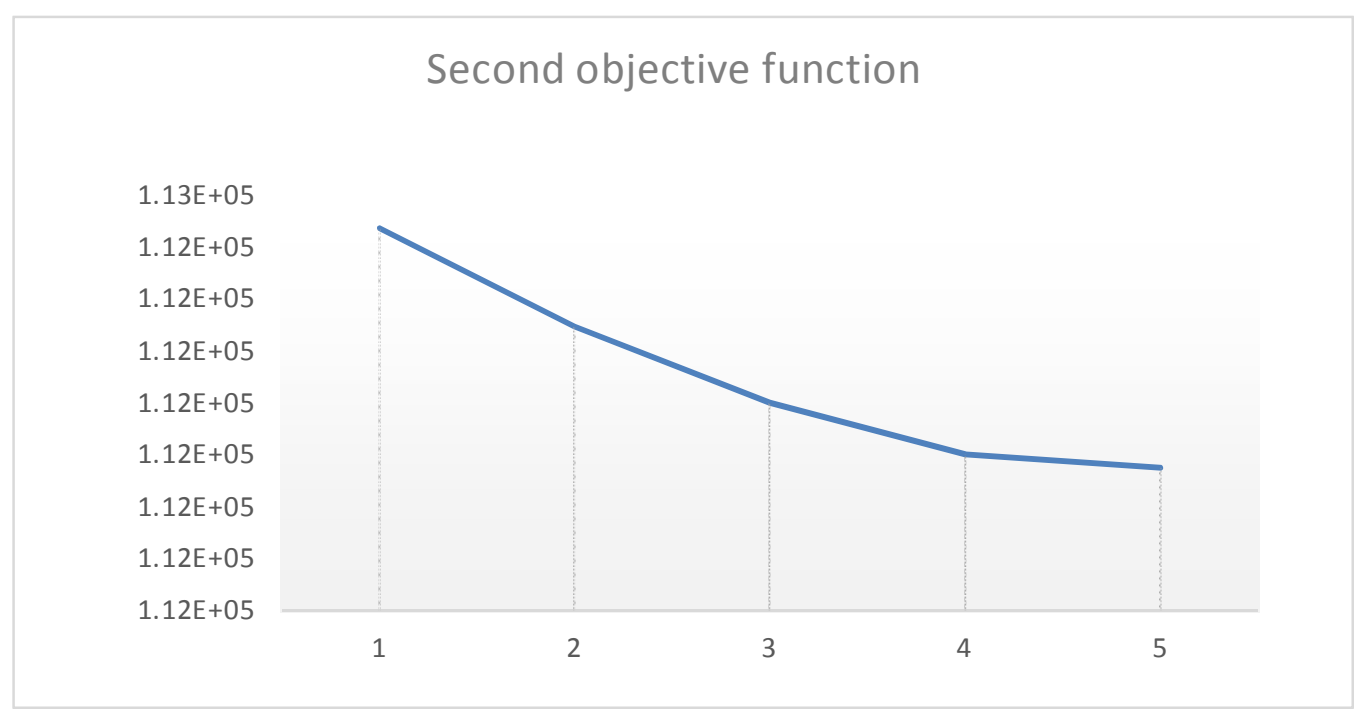

Fig. 5. The effect of changing suppliers capacities on Second objective functions 


\subsection{The effect of changing available time on objective functions}

By reducing the available time, the costs increase because by decreasing the available time the organization has to buy machines for factory or buy more products from suppliers which increase the costs. Apart from that, from the time interval uniform $(1800,2000)$ to time interval uniform $(1900$, 2100) the costs do not change for the reason that the available time does not meet the time needed to produce and distribute. The $\mathrm{CO}_{2}$ emissions function decrease because by decreasing the available time the organization buy products from suppliers rather than produced them and this decreases the second objective function.

Table 5

The effect of decease available time $n$ two objective functions

\begin{tabular}{ccc}
\hline Available time & Objective function 1 & Objective function 2 \\
\hline $\mathrm{u}(2100,2300)$ & 5677083.6 & $1.12 \mathrm{E}+08$ \\
$\mathrm{u}(1900,2100)$ & 5683954.9 & $1.12 \mathrm{E}+08$ \\
$\mathrm{u}(1800,2000)$ & 5683225.0 & $1.13 \mathrm{E}+08$ \\
$\mathrm{u}(1600,1800)$ & 5696299.8 & $1.13 \mathrm{E}+08$ \\
\hline
\end{tabular}

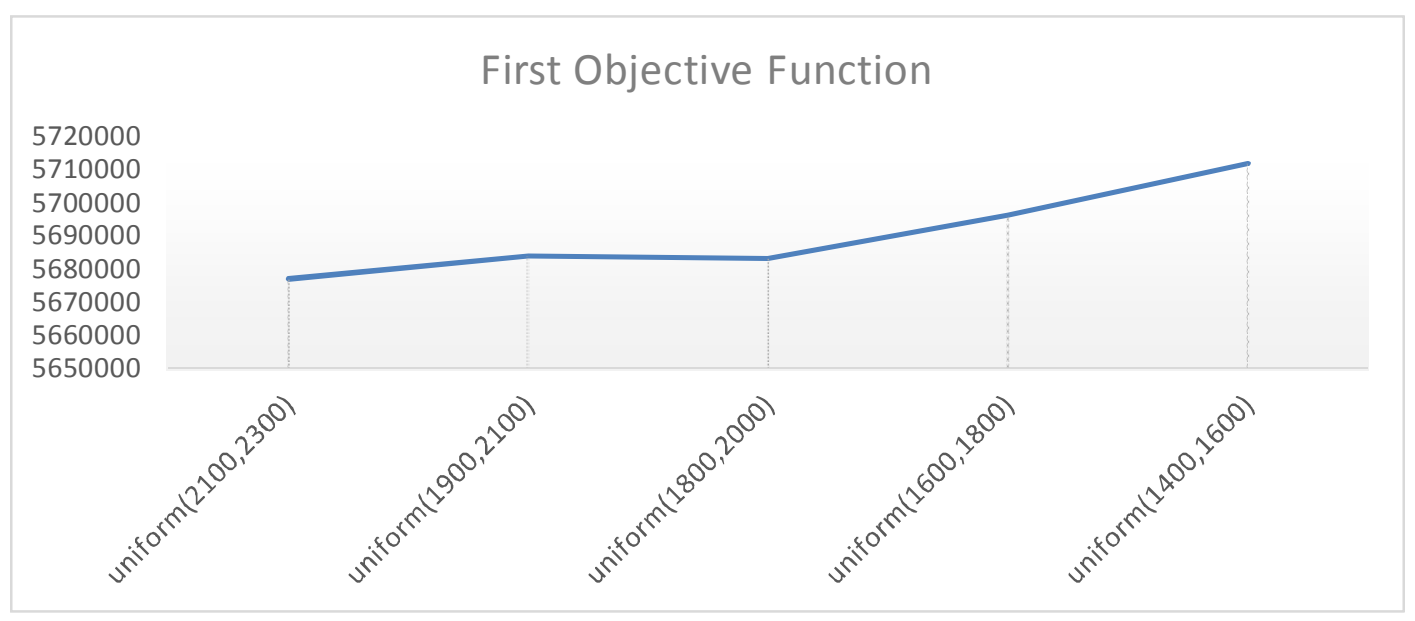

Fig. 6. The effect of changing available time on first objective functions

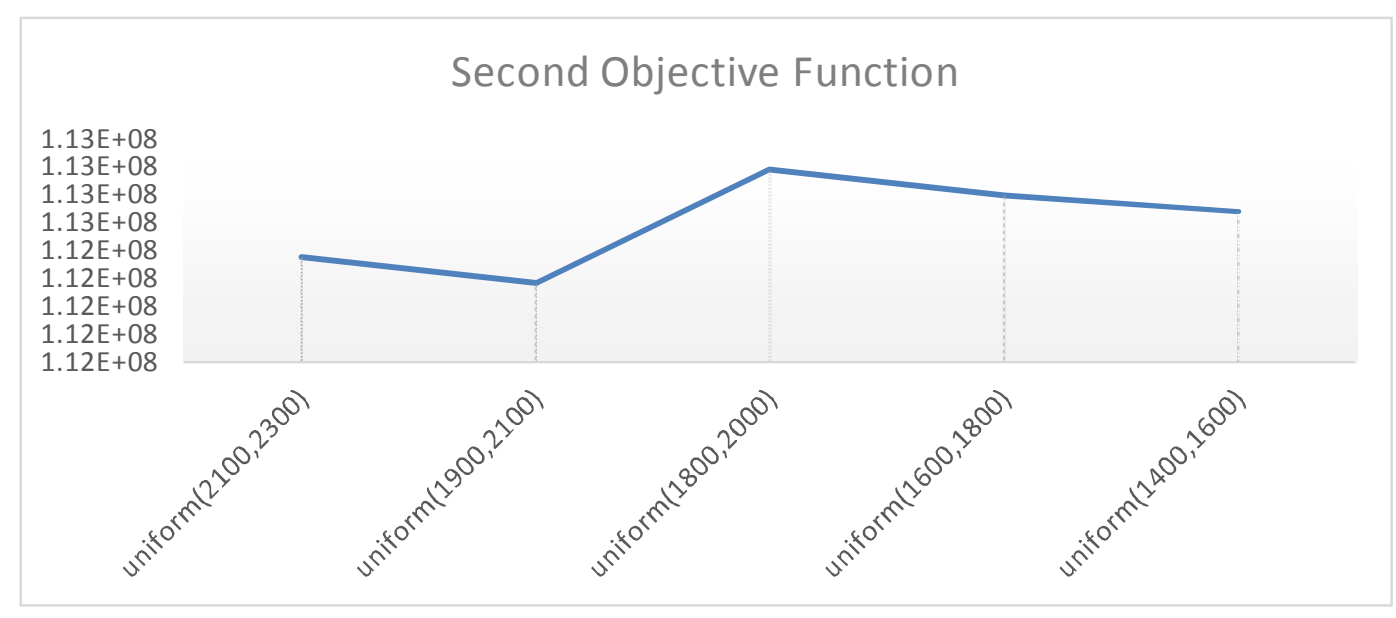

Fig. 7. The effect of changing available time on second objective functions 


\section{Conclusion}

The significance of supply chain design was its effects on facilities location, the flow of goods and services, and satisfaction level. Recently, the costs of defect in goods, satisfaction degree, reverse flows in recovery centers and recycle centers have been considered. This paper examined both forward production, distribution_and backward recovery, recycle, selling recycle product_flows and optimized the customer satisfaction level. It provided a balance between economic cost and environmental issues under uncertainty. The uncertain parameters were managed by using fuzzy programming. The fuzzy model first was turned to crisp auxiliary model, and then the proposed model was solved by the combined approach of Jimenez, TH. The experimental results were examined by both GAMS software and NSGA-II algorithm. It was axiomatic that the conflict of two objective function, and the performance of GAMS and NSGA-II proved the validity and reliability of the model. The sensitivity analyses showed the effects of changing some key parameters such as available time, and suppliers' capacity on both objective functions.

\section{References}

Ambrosino, D., \& Scutella, M. G. (2005). Distribution Network Design: New Problems and Related Models. European Journal of Operational Research, 165, 610-624.

Arenas Parra, M., Bilbao Terol, A., Pérez Gladish, B., \& Rodrí guez Urí ą M. V. (2005). Solving a multiobjective possibilistic problem through Compromise programming. European Journal of Operational Research, 164, 748-759.

Barros A. I., Dekker R., \& Scholten V. (1998). A two-level network for recycling sand: a case study. European Journal of Operational Research, 110, 199-214.

Daskin, M. S. (1995). Network and Discrete Location: Models, Algorithms, and Applications. Wiley, New York.

Drezner, Z., wesolowsky, G. O. (2003). Network design: selection and design of links and facility location. Transportation Research, 37, 241-256.

Fleischmann, M., Bloemhof-Ruwaard, J., Dekker R., van der Laan E., van Nunen J., \& van Wassenhove L. (1997). Quantitative models for reverse logistics: a review. European Journal of Operational Research, 103, 1-17.

Hassanzadeh Amin S., \& Zhang, G. (2013). A multi-objective facility location model for closed-loop supply chain network under uncertain demand and return. Applied Mathematical Modelling, 37, 4165-4176.

Hugo A., \& Pistikopoulos E. N. (2005). Environmentally conscious long-range planning and design of supply chain networks. Journal of Cleaner Production, 13, 1471-1491.

Ilgin, M.A., Surendra, M., \& Gupta, S.M. (2010). Environmentally conscious manufacturing and product recovery (ECMPRO): a review of the state of the art. Journal of Environmental Management, 91, 563-591.

Jayaraman, V., Guige Jr., V. D. R., \& Srivastava R. (1999). A closed-loop logistics model for manufacturing. The Journal of the Operational Research Society, 50, 497-508.

Jayaraman V., Patterson R. A., \& Rolland, E. (2003). The design of reverse distribution networks: models and solution procedures. European Journal of Operational Research, 150, 128-149.

Jiménez, M. (1996). Ranking fuzzy numbers through the Comparison of its expected intervals. International Journal of Uncertainty, Fuzziness and Knowledge-Based Systems, 4, 379-388.

Klibi, W., Martel, A., \& Guitouni, A. (2010). The design of robust value-creating supply chain networks: a critical review. European Journal of Operational Research, 203, 283-293.

Lu, Z., \& Bostel, N. (2007). A facility location model for logistics systems including reverse flows: the case of remanufacturing activities. Computers \& Operations Research, 34, 299-323.

Melkote, S., \& Daskin, M. S. (2001). Capacitated facility location/network design problem. European Journal of Operational Research, 129, 481-495.

Melo, M. T., Nickel, S., \& Gama, F. S. (2009). Facility location and supply chain management. European Journal of Operational Research, 196, 401-412. 
Nga Thanh, P., Bostel, N., \& Peton, O. (2008). A dynamic model for facility location in the design of complex supply chains. International Journal of Production Economics, 113, 678-693.

Ozkır V., \& Başligil, H. (2013). Multi-objective optimization of closed-loop supply chains in uncertain environment. Journal of Cleaner Production, 41, 114-125.

Pati, R., Vrat, P., \& Kumar, P. (2008). A goal programming model for paper recycling system. Omega, 36, 405-417.

Pishvaee, M. S., Farahani, R. Z., \& Dullaert, W. (2010). A memetic algorithm for bi-objective integrated forward/reverse logistics network design. Computers \& Operations Research, 37, $1100-1112$.

Pishvaee, M. S., Rabbani, M., \& Torabi, S. A. (2011). A robust optimization approach to closed-loop supply chain network design under uncertainty. Applied Mathematical Modelling, 35, 637-649.

Pishvaee, M. S., \& Razmi, J. (2012). Environmental supply chain network design using multiobjective fuzzy mathematical programming. Applied Mathematical Modelling, 36, 3433-3446.

Pishvaee, M. S., Razmi, J., \& Torabi, S. A. (2012). Robust possibilistic programming for socially responsible supply chain network design: A new approach. Fuzzy Sets and Systems, 206, 1-20.

Pishvaee, M. S., \& Shakouri, H. (2009). A System Dynamics Approach for Capacity Planning and Price Adjustment in a Closed-Loop Supply Chain. IEEE, Computer Modeling and Simulation EMS 09: 435-439.

Pishvaee, M. S., \& Torabi, S. A. (2010). A possibilistic programming approach for closed-loop supply chain network design under uncertainty. Fuzzy Sets and Systems, 161, 2668-2683.

Quariguasi Frota Neto, J., Bloemhof-Ruwaard, J. M., van Nunen, J. A. E. E., \& van Heck, E. (2008). Designing and evaluating sustainable logistics networks. International Journal of Production Economics, 111, 195-208.

Quariguasi Frota Neto, J., Walther G., Bloemhof, J., van Nunen, J. A. E. E., \& Spengler, T. (2009). A methodology for assessing eco-efficiency in logistics networks. European Journal of Operational Research, 193, 670-682.

Sayed, M., Afia, N., \& Kharbotly, A. (2010). A stochastic model for forward-reverse logistics network design under risk. Computers \& Industrial Engineering, 58, 423-431.

Torabi, S. A., \& Hassini, E. (2008). An interactive possibilistic programming approach for multiple objective supply chain master planning. Fuzzy Sets and Systems, 159, 193-214.

Wang H. F., \& Hsu, H. W. (2010). Resolution of an uncertain closed-loop logistics model: An application to fuzzy linear programs with risk analysis. Journal of Environmental Management, 91, 2148-2162.

Wang, R. C., \& Liang, T. F. (2005). Applying possibilistic linear programming to aggregate production planning. International Journal of Production Economics, 98, 328-341.

Yager, R. R. (1981). A procedure for ordering fuzzy subsets of the unit interval. Information Sciences, 24, 143-161. 